\title{
Molecular mechanism of the intramembrane cleavage of the $\beta$-carboxyl terminal fragment of amyloid precursor protein by $\boldsymbol{\gamma}$-secretase
}

\author{
Maho Morishima-Kawashima* \\ Laboratory of Neuroscience, Graduate School of Pharmaceutical Sciences, Hokkaido University, Sapporo, Japan
}

Edited by:

Raquel Marin, Universidad de La

Laguna, Spain

Reviewed by:

Manuel Torres, Lipopharma

Therapeutics S.L., Spain

Maria Dolores Ledesma, Centro de

Biología Molecular Severo Ochoa,

Spain

*Correspondence:

Maho Morishima-Kawashima,

Laboratory of Neuroscience,

Graduate School of Pharmaceutical

Sciences, Hokkaido University, Kita

12-Nishi 6, Kita-ku, Sapporo

060-0812, Japan

e-mail:maho@pharm.hokudai.ac.jp
Amyloid $\beta$-protein $(A \beta)$ plays a central role in the pathogenesis of Alzheimer's disease, the most common age-associated neurodegenerative disorder. $A \beta$ is generated through intramembrane proteolysis of the $\beta$-carboxyl terminal fragment ( $\beta C T F)$ of $\beta$-amyloid precursor protein (APP) by $\gamma$-secretase. The initial cleavage by $\gamma$-secretase occurs in the membrane/cytoplasm boundary of the $\beta C T F$, liberating the APP intracellular domain (AICD). The remaining $\beta C T F s$, which are truncated at the $C$-terminus (longer $A \beta s$ ), are then cropped sequentially in a stepwise manner, predominantly at three residue intervals, to generate $A \beta$. There are two major $A \beta$ product lines which generate $A \beta 40$ and $A \beta 42$ with concomitant release of three and two tripeptides, respectively. Additionally, many alternative cleavages occur, releasing peptides with three to six residues. These modulate the A $\beta$ product lines and define the species and quantity of $A \beta$ generated. Here, we review our current understanding of the intramembrane cleavage of the $\beta$ CTF by $\gamma$-secretase, which may contribute to the future goal of developing an efficient therapeutic strategy for Alzheimer's disease.

Keywords: amyloid $\beta$-protein, $\gamma$-secretase, amyloid precursor protein, Alzheimer's disease, intramembrane proteolysis

\section{INTRODUCTION}

Amyloid $\beta$-protein $(\mathrm{A} \beta)$ is a key molecule in the pathogenesis of Alzheimer's disease (AD), which is the most common dementia among elderly people and is characterized by memory loss and cognitive decline. The $\mathrm{A} \beta$ is a $37-43$ amino acid hydrophobic protein that constitutes senile plaques, a neuropathological hallmark of $\mathrm{AD}$ (Reviewed in Selkoe, 2011). Among the various $\mathrm{A} \beta$ species with variable $C$-terminal lengths, $A \beta 42$ is believed to be the most neurotoxic and aggregation-prone species (Iwatsubo et al., 1994; Kuperstein et al., 2010), and its production and deposition can be enhanced by familial AD (FAD)-associated mutations. Thus, the regulation of the $A \beta$ produced is a current central issue in the therapeutics for $\mathrm{AD}$; although it has not yet been successful (Extance, 2010).

$A \beta$ is produced from $\beta$-amyloid precursor protein (APP) through successive cleavages mediated by two aspartyl membrane proteases, $\beta$ - and $\gamma$-secretases. The ectodomain shedding of APP by $\beta$-secretase generates a 99 amino-acid $\beta$-carboxyl terminal fragment ( $\beta \mathrm{CTF})$, an immediate substrate for $\gamma$-secretase. The generated $\beta$ CTF is then processed by $\gamma$-secretase within the transmembrane domain, releasing A $\beta$ and the APP intracellular domain (AICD) (De Strooper et al., 2012). The latter cleavage has been enigmatic because the proteolysis occurs within the membrane, that is, in the hydrophobic environment of the lipid bilayer. $\gamma$-Secretase is a membrane-embedded atypical protease comprised of four integral membrane proteins: presenilin (PS) 1 or PS2, nicastrin, Aph-1, and Pen-2 (De Strooper et al., 2012). PS serves as the catalytic subunit (Wolfe et al., 1999). The three other members play a role in the stabilization and maturation of the complex. Nicastrin has also been implicated in the substrate binding (Shah et al., 2005). Besides the $\beta$ CTF, $\gamma$-secretase cleaves many type I membrane proteins including the Notch receptor, which is responsible for cellular signaling during development and in adults (De Strooper and Annaert, 2010). Recent structural studies for $\gamma$-secretase revealed that two catalytic Asp residues on the transmembrane domains 6 and 7 of PS face the water-accessible hydrophilic environment and act to catalyze the substrate proteolysis (Sato et al., 2006; Tolia et al., 2006; Li et al., 2013). Water can gain access through the cavity surrounded by multiple transmembrane domains, as shown in other PS family proteases ( $\mathrm{Hu}$ et al., 2011; Li et al., 2013) and also in $\gamma$-secretase (Lu et al., 2014) very recently. In contrast, the molecular mechanism underlying the intramembrane cleavage of a substrate by $\gamma$-secretase is less clear. A better understanding of how the $\beta$ CTF is processed to $\mathrm{A} \beta$ through intramembrane proteolysis by $\gamma$-secretase may help establish an efficient disease modifying drug that specifically regulates $\mathrm{A} \beta 42$ production and/or does not have the adverse side effects derived from the suppression of other substrate cleavages (such as the Notch receptor) (Extance, 2010). The present review covers the recent progress in the understanding of the molecular mechanism of the intramembrane proteolysis of the $\beta C T F$ by $\gamma$-secretase.

\section{$\gamma$-CLEAVAGE AND $\varepsilon$-CLEAVAGE $\varepsilon$-CLEAVAGE, A NOVEL FORM OF CLEAVAGE}

Intramembrane cleavage of the $\beta$ CTF by $\gamma$-secretase generates an $\mathrm{A} \beta$ of $\sim 4 \mathrm{kDa}$ and an AICD of $\sim 6 \mathrm{kDa}$ (Figure 1A). The AICD, a counterpart of the $A \beta$, is unstable in cells and has 


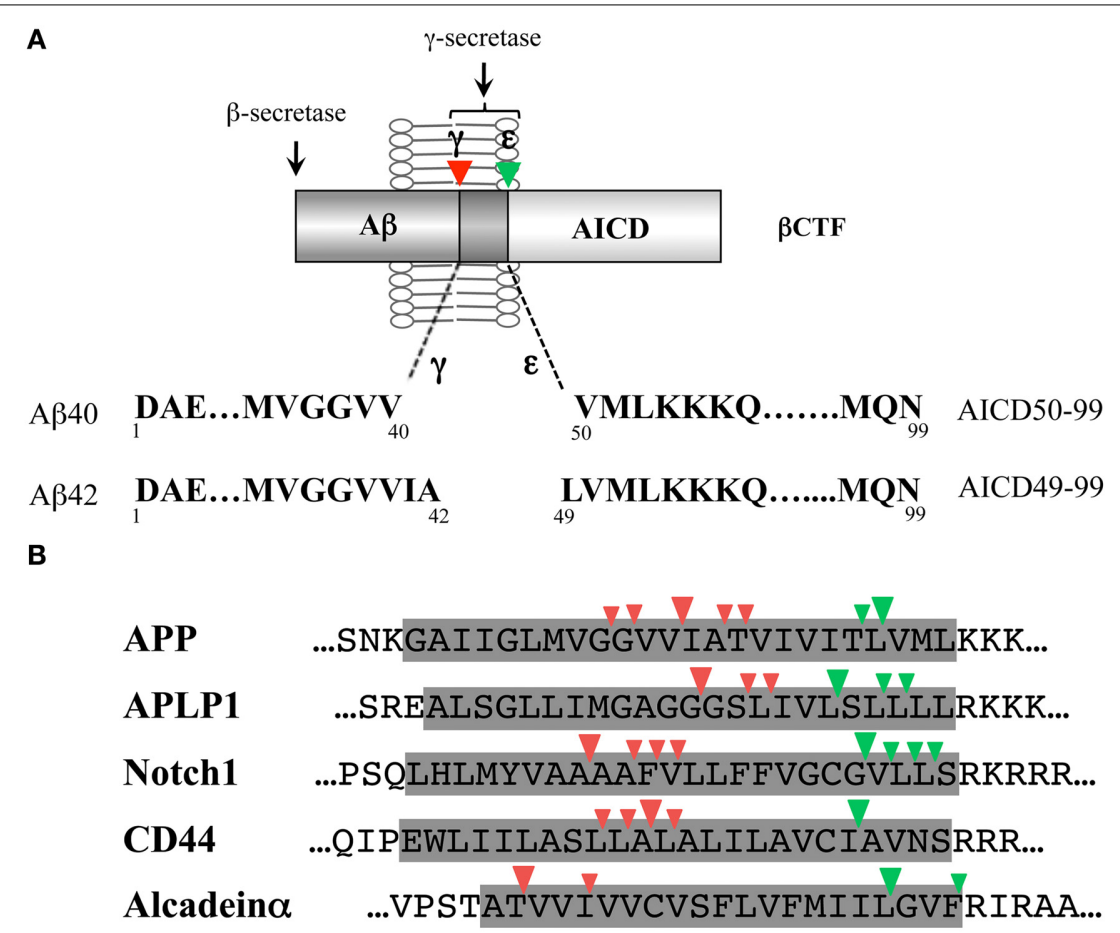

FIGURE $1 \mid \gamma$-Cleavage and $\varepsilon$-cleavage by $\gamma$-secretase. (A) Schematic illustration of $\gamma$ - and $\varepsilon$-cleavages of the $\beta$ CTF by $\gamma$-secretase. $\gamma$-Cleavage generates $A \beta 40$ and $A \beta 42$; while, $\varepsilon$-cleavage generates AICD50-99 and AICD49-99. There is a link between $A \beta 40$ and AICD50-99 and between A 42 and AICD49-99. (B) Comparison of the $\gamma$-secretase-dependent intramembrane cleavage sites of various $\gamma$-secretase substrates. $\gamma$-Cleavages (site 4 cleavages) and $\varepsilon$-cleavages (site 3 cleavages) are shown by red and green arrowheads, respectively. The shaded area represents the predicted transmembrane domain. Either the human or rodent sequence is shown based on the identification studies. The three residue-spaced cleavages apply to the major $\gamma^{-}$and $\varepsilon$-cleavage sites of APP, APLP1, Notch1, and CD44. In alcadein $\alpha, \gamma$ - and $\varepsilon$-cleavages occur at three residue intervals, respectively. been postulated to start at either Ile41 or Thr43 (A $\beta$ numbering). However, protein sequencing and mass spectrometric analysis of the AICD generated in vitro by cell-free or reconstituted $A \beta$ generation systems revealed that the AICD starts at Val50 or Leu49 (A $\beta$ numbering) (Gu et al., 2001; Sastre et al., 2001) and production of these AICDs was $\gamma$-secretase dependent. The novel cleavage to generate the AICD (referred to as $\varepsilon$-cleavage) (Weidemann et al., 2002) was located $\sim 10$ amino acids downstream of the $\mathrm{A} \beta$ generation sites ( $\gamma$-cleavages), a few residues inside the membrane-cytoplasmic boundary, and is very similar to the site 3 cleavage of the Notch receptor (Schroeter et al., 1998). In the Notch signaling, $\gamma$-secretasedependent Notch site 3 cleavage generates Notch intracellular domain (NICD) that mediates the signaling cascade in a variety of cell biological processes (De Strooper and Annaert, 2010), indicating the functional significance of this cleavage. Thus, $\gamma$ secretase cleaves the transmembrane domain of the $\beta$ CTF in at least two sites: $\gamma$-cleavage generates $A \beta$ while $\varepsilon$-cleavage generates the AICD. These dual cleavages are not inherent to the $\beta C T F$ of the APP, but also occur in other $\gamma$-secretase substrates, such as APLP1/2 (Gu et al., 2001; Yanagida et al., 2009), Notch (Schroeter et al., 1998; Okochi et al., 2002; Tagami et al., 2008), CD44 (Okamoto et al., 2001; Lammich et al., 2002), and alcadeins $\alpha / \beta / \gamma$ (Hata et al., 2009; Piao et al., 2013) (Figure 1B).

\section{A POTENTIAL LINK BETWEEN $\boldsymbol{\gamma}$ - AND $\varepsilon$-CLEAVAGES}

The $\varepsilon$-cleavage is heterogeneous, similar to the $\gamma$-cleavage and the two molecular species of the A $\beta$ and AICD that are generated appear to be linked (Figure 1A). In cells expressing wild-type APP and/or wild-type PS1/2, A $\beta 40$ and AICD50-99 were predominant, and A $\beta 42$ and AIDC49-99 were minor species. When various forms of FAD-mutant APP or FAD-mutant PS1/2 were expressed in cells, the proportion of $A \beta 42$ vs. A $\beta 40$ increased with a concomitant increase in the proportion of AICD49-99, although the relationship was not the same (Sato et al., 2003). A low concentration of the difluoro ketone peptidomimetic $\gamma$-secretase inhibitor DFK-167, (N-[(S)-2,2-difluoro-3-oxo-4-[(Boc-L-ValL-Ile-)amino]pentanoyl]-L-Val-L-Ile-OMe), induced an increase in A $\beta 42$, which also caused an increase in AICD49-99 (Sato et al., 2003). Thus, there is a link between $A \beta 40$ and AICD50-99 and between A $\beta 42$ and AICD49-99. A close relation between $\gamma$ - and $\varepsilon$-cleavages was also suggested by the observation that APP FADmutations close to the $\varepsilon$-cleavage site (V717F, L723P) and the $\gamma$-cleavage site (T714I, V715A) influenced $\varepsilon$-cleavage as well as $\gamma$-cleavage, with remarkable increases in A $\beta 42$ and AICD49-99 (Kakuda et al., 2006; Dimitrov et al., 2013).

\section{$\varepsilon$-CLEAVAGE PRECEDES $\boldsymbol{\gamma}$-CLEAVAGE}

The potential link between A $\beta 42$ and AICD49-99 raises a question: which cleavage, $\gamma$ - or $\varepsilon$-, occurs first? It is likely that the 
$\varepsilon$-cleavage occurs first for the following reasons. First, the $\varepsilon$ cleavage site is located in close proximity to the cytoplasm, where water is available. In addition, the longest AICD detected so far in studies was AICD49-99. Thus, the $\varepsilon$-cleaved $\beta C T F s$ of longer $A \beta$ s $(A \beta 49$ and $A \beta 48)$ must then undergo $\gamma$-cleavage for $A \beta$ generation. To test this proposal, $A \beta 49$ and $A \beta 48$ were overexpressed in cells and the molecular species of $A \beta$ generated were investigated (Funamoto et al., 2004). The expression of A $\beta 49$, a counterpart of AICD50-99, generated predominantly $\mathrm{A} \beta 40$; while, the expression of $\mathrm{A} \beta 48$, a counterpart of AICD4999 , preferentially produced $A \beta 42$. These findings support the idea that $\varepsilon$-cleavage occurs first. Note that the expression of $A \beta 51$, which is three residues longer than $A \beta 48$, also produced predominantly $A \beta 42$ (Funamoto et al., 2004). Thus, longer $A \beta$ s generated through $\varepsilon$-cleavage are processed to $A \beta 40 / A \beta 42$ by $\gamma$-secretase. Moreover, the initial $\varepsilon$-cleavage sites determine the subsequent $\gamma$-cleavage sites and the type of $\mathrm{A} \beta$ species produced.

\section{STEPWISE SUCCESSIVE PROCESSING OF LONGER A $\beta$ s BY $\gamma$-SECRETASE GENERATES A 340 AND A $\beta 42$ LONGER A $\beta$ S ARE INTERMEDIATE PRODUCTS PRESENT IN CELLS}

When $\varepsilon$-cleavage precedes $\gamma$-cleavage, longer $A \beta$ s should be produced. Thus, it is important to identify these intermediate molecules. The corresponding intermediates, which are $\mathrm{A} \beta$ species longer than $A \beta 1-42$, are retained in the membrane in minimal amounts, if any. These $A \beta$ species were immunoprecipitated with the $A \beta \mathrm{N}$-terminus specific antibody from the membrane fraction and analyzed by Western blotting using a modified SDS/urea gel system that could distinguish A $\beta 37$ through $A \beta 49$, even when the $A \beta$ species varied by only one residue ( $Q$ i-Takahara et al., 2005). Longer $A \beta$ s, including $A \beta 43, A \beta 45, A \beta 46$, and $A \beta 48$, were identified in the cells and in mouse brains. Their production was $\gamma$-secretase dependent. In our hands, $A \beta 49$ was hardly detectable. In cells expressing wild-type APP and/or wild-type PS, the major intracellular $A \beta$ species were $A \beta 40, A \beta 43$, and $A \beta 46$, and the minor ones were $A \beta 42, A \beta 45$, and $A \beta 48$. In cells expressing mutant APP or mutant PS, decreases in $A \beta 40$ and increases in $A \beta 42$ sometimes accompanied decreased levels of $A \beta 43$ and $A \beta 46$ and increased levels of $A \beta 45$ and $A \beta 48$; however, the coordination was not always obvious (Qi-Takahara et al., 2005).

Thus, $\gamma$-secretase cleaves the transmembrane domain of the $\beta C T F$ at multiple sites (Figure 2A). The cleavage site between the $\gamma$-and $\varepsilon$-cleavage sites is called the $\zeta$-site (Zhao et al., 2004). These cleavage sites appear to be divided into two groups, the sites relevant to $A \beta 40$ production $(A \beta 43, A \beta 46, A \beta 49)$ and those relevant to $A \beta 42$ production $(A \beta 45, A \beta 48)$. The cleavage at three residue intervals is a prominent property in each group. This notion is supported also by the observation that the V721K APP mutation led to increased AICD47-99 (a counterpart of A $\beta 46$ ) and a concomitant increase in $\mathrm{A} \beta 40$.

\section{STEPWISE SUCCESSIVE PROCESSING BY $\gamma$-SECRETASE GENERATES $\mathbf{A} \beta$}

Interestingly, dose-dependent treatment with DAPT $(N-[N-(3,5-$ difluorophenacetyl)-L-alanyl]-S-phenylglycine $t$-butyl ester), a potent dipeptide $\gamma$-secretase inhibitor, caused differential accumulations of longer $A \beta s$ in the cells that inducibly expressed the

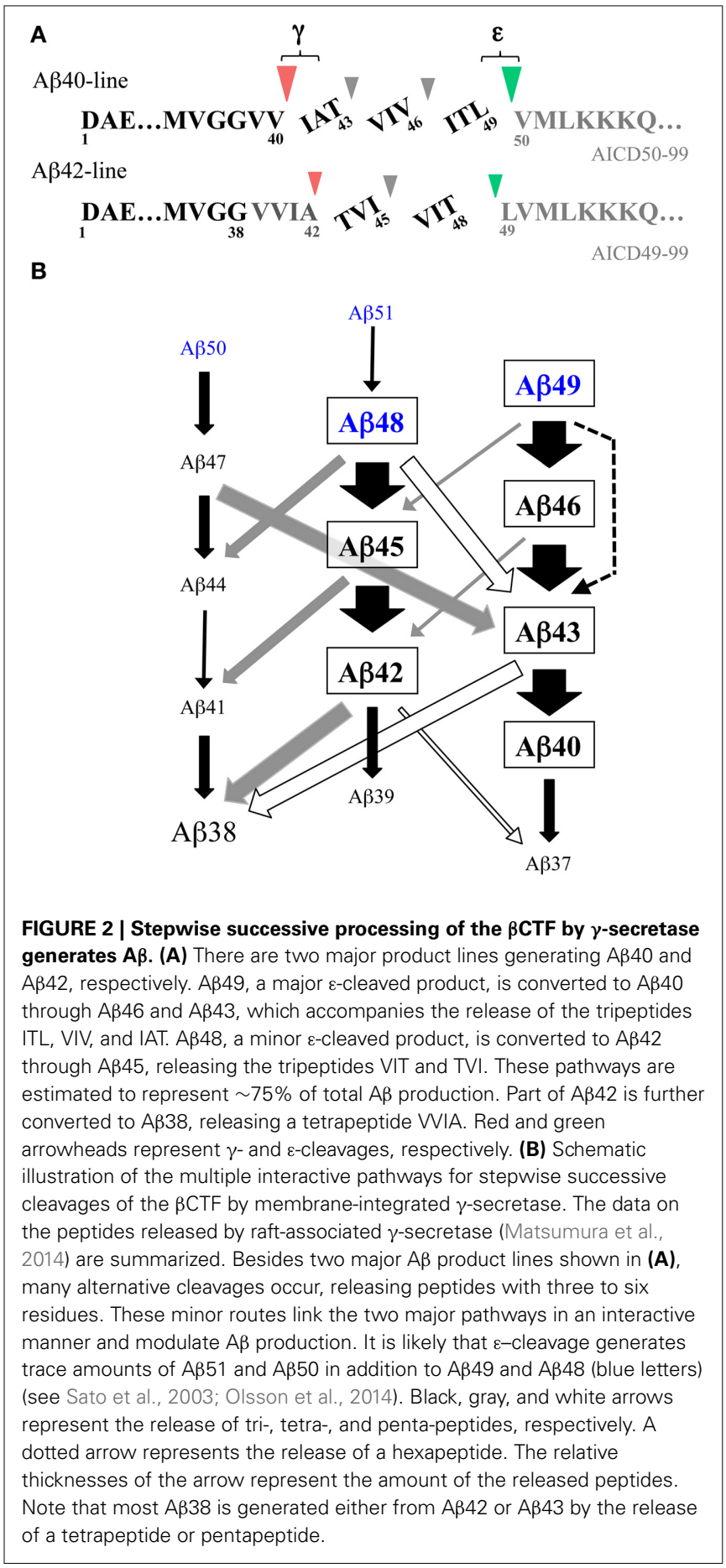

$\beta C T F$ (Qi-Takahara et al., 2005). A decrease in A $\beta 40$ levels accompanied a transient increase in $A \beta 43$, which, in turn, brought about a transient increase in $A \beta 46$. One plausible explanation for this observation would be the precursor-product relationship. Suppression of $A \beta 40$ results in accumulation of its precursor molecule, $A \beta 43$, and subsequently, suppression of $A \beta 43$ induces accumulation of its precursor $A \beta 46$. Thus, it is reasonable to speculate that $A \beta 40$ is produced successively from $A \beta 46$ through $A \beta 43$. In contrast to the wild-type cells, dose-dependent 
treatment with DAPT did not induce dramatically different intracellular accumulations of $\mathrm{A} \beta$ in a consistent manner in mutant PS cells (Yagishita et al., 2006). PS2 cells with the N141I mutation exhibited a remarkable decrease in $\mathrm{A} \beta 42$ and a concomitant increase in A $\beta 45$, while M233T mutant PS1 cells showed a decrease in $\mathrm{A} \beta 42$, which accompanied a slight transient increase in $\mathrm{A} \beta 48$.

These results led us to propose the stepwise successive processing model by $\gamma$-secretase for $\mathrm{A} \beta$ generation (Qi-Takahara et al., 2005) (Figure 2A). In this model, $\gamma$-secretase cleaves the $\beta C T F$ first at the $\varepsilon$-cleavage site close to the membrane-cytoplasm boundary and the truncated $\beta \mathrm{CTF}$ (longer $\mathrm{A} \beta \mathrm{s}$ ) generated is processed from the $\mathrm{C}$-terminus at every third residue. According to the model, $A \beta 49$, a major $\varepsilon$-cleaved product, is converted to $\mathrm{A} \beta 40$ through $\mathrm{A} \beta 46$ and $\mathrm{A} \beta 43$, releasing the tripeptides ITL, VIV, and IAT. The other minor $\varepsilon$-cleaved product, $A \beta 48$, is converted to $A \beta 42$ through $A \beta 45$, releasing the tripeptides VIT and TVI. Consistent with this model, treatment of cells with DAPT caused accumulation of $A \beta 46$ in lipid rafts, which was processed to $A \beta 40$ and $A \beta 43$, but not $A \beta 42$, in a $\gamma$-secretase-dependent manner through in vitro incubation of the isolated rafts (Yagishita et al., 2008).

\section{TRIPEPTIDES ARE RELEASED CONCOMITANTLY WITH A $\beta$ GENERATION}

The identification of the tripeptides released by $\gamma$-secretase during $A \beta$ generation provides convincing evidence for this cleavage model. These tripeptides were directly identified and quantified in the reaction mixture of a CHAPSO-solubilized reconstituted $\gamma$-secretase system using liquid chromatography with tandem mass spectrometry (LC-MS/MS) (Takami et al., 2009); in this system, the $\beta \mathrm{CTF}$ purified from Sf9 cells was used as a substrate. The predicted five tripeptides were all identified by LC-MS/MS. Three tripeptides in the putative A $\beta 40$-product line (IAT, VIV, and ITL) and two tripeptides in the putative A $\beta 42$ product line (TVI and VIT) were released concomitantly with $\mathrm{A} \beta$ generation. Additionally, a released tetrapeptide, VVIA, was identified, although in relatively low amounts (Figure 2A). This finding indicated that a part of $A \beta 42$ is converted to $A \beta 38$ by releasing VVIA. The release of those peptides was suppressed by $\gamma$-secretase inhibitors, indicating that their generation was $\gamma$ secretase-dependent. Similar tri- and tetrapeptides were released using synthetic $A \beta$ peptides as substrates (Okochi et al., 2013). The quantification of the released peptides further validated the accuracy of the model (Takami et al., 2009). The relative relationships of the peptides were: ITL $>$ VIV $>$ IAT and VIT $>$ TVI $>>$ VVIA, which fitted the model. The A $\beta$ levels estimated by the tripeptide amounts, according to the model, corresponded well with the levels determined by Western blotting. Thus, the proposed stepwise processing model is reasonable and there are two product lines: $\mathrm{A} \beta 49->\mathrm{A} \beta 46->\mathrm{A} \beta 43->\mathrm{A} \beta 40$ and $\mathrm{A} \beta 48->$ $\mathrm{A} \beta 45$-> A 342 (-> A $\beta 38)$ (Figure 2A).

\section{MULTIPLE INTERACTIVE PATHWAYS FOR STEPWISE SUCCESSIVE PROCESSING GENERATE $A \boldsymbol{\beta}$}

Lipid rafts are detergent-resistant membrane microdomains enriched in cholesterol and sphingolipids and play a significant role in A $\beta$ generation in cells (Vetrivel and Thinakaran, 2010).
These rafts exclusively contain all four components required for the active $\gamma$-secretase complex: the PS N-terminal fragment/Cterminal fragment, mature nicastrin, Aph-1, and Pen-2 (Wada et al., 2003; Vetrivel et al., 2004), indicating that active $\gamma$-secretase is present in lipid rafts (Hur et al., 2008). In addition, the lipid composition in the membrane of the rafts is favorable for $\gamma$ secretase activities: both cholesterol and sphingolipids have been shown to enhance its activities (Osenkowski et al., 2008). Thus, these lipid rafts can provide the proper lipid environment for $\mathrm{A} \beta$ generation, as seen in the in vitro $\mathrm{A} \beta$ generation systems, which exhibited higher $\gamma$-secretase activity in lipid rafts (Wada et al., 2003; Hur et al., 2008).

The membrane integrity of $\gamma$-secretase was not considered in the studies discussed above. Therefore, we assessed whether membrane-integrated $\gamma$-secretase followed the cleavage model using $\gamma$-secretase associated with lipid rafts. The reaction mixture of the in vitro reconstituted $\gamma$-secretase system with lipid raft-associated $\gamma$-secretase was subjected to LC-MS/MS analyses to identify the small peptides released from the transmembrane domain of the $\beta$ CTF during $A \beta$ generation (Matsumura et al., 2014). Similar to the CHAPSO-solubilized system, the predicted 5 tripeptides, IAT, VIV, ITL, TVI, and VIT, and the tetrapeptide, VVIA, were released in a $\gamma$-secretase-dependent manner with $A \beta$ generation. The same quantitative relationships, ITL $>$ VIV $>$ IAT and VIT $>$ TVI $>>$ VVIA, were also present. Thus, raft-associated $\gamma$-secretase cleaves the transmembrane domain of the $\beta$ CTF in a stepwise successive manner at every third or fourth residue to generate $A \beta 40$ and $A \beta 42(A \beta 38)$. However, $A \beta$ generation by raftassociated $\gamma$-secretase accompanied the release of novel pentaand hexapeptides, as well as tri- and tetrapeptides. Although they were in low amounts and the original two pathways that generated $\mathrm{A} \beta 40$ and $\mathrm{A} \beta 42$ amounted to $\sim 75 \%$ of total $\mathrm{A} \beta$ production (Matsumura et al., 2014), the clipping of the novel peptides, in particular pentapeptides, links the above two major pathways at several points and allows for an alternative route for successive cleavages (Figure 2B). The presence of multiple interactive pathways for the stepwise cleavages of the $\beta \mathrm{CTF}$ could modulate the nature of the species and the quantity of $A \beta$ generated. In fact, these interactive pathways could provide a better explanation for several previous studies apparently inconsistent with the model that affords two $\mathrm{A} \beta$ product lines (see Matsumura et al., 2014). Similar three- to six-residue peptides were also released and identified in the cell-free $A \beta$ generation system with an endogenous substrate, where no detergent was used (Olsson et al., 2014). In this study, small amounts of A $\beta 40$ and $A \beta 42$ continued to be processed in a stepwise manner, being further converted into smaller $A \beta$ s such as $A \beta 37, A \beta 36$, and $A \beta 34$ (Olsson et al., 2014). It is worth noting that $A \beta 38$ and $A \beta 43$ may be generated via three routes, releasing a tri-, tetra-, and penta-peptide, respectively, (Figure 2B). $\gamma$-Secretase modulators (GSMs), such as GSM-1 ((2S,4R)-1-[(R)-1-(4-chlorophenyl-4methylpentyl)-2-(4-trifluoromethylphenyl)piperidin-4-yl]acetic acid), can selectively lower $A \beta 42$ levels and are a prospective therapeutic tool for $\mathrm{AD}$. These modulating compounds enhanced all three routes that generate $A \beta 38$ and the conversion of $A \beta 40$ to $A \beta 37$. Significant decreases in conventional $A \beta s(A \beta 42, A \beta 43$, and $A \beta 40)$ occurred as well as increases in the levels of shorter 
A $\beta$ s (A $\beta 38$ and A $\beta 37$ ) (Takami et al., 2009; Okochi et al., 2013; Matsumura et al., 2014; Olsson et al., 2014). Thus, the influence of GSMs is not limited to a single pathway (the conversion of $\mathrm{A} \beta 42$ to $\mathrm{A} \beta 38$ ), but advances the stepwise cleavage by $\gamma$-secretase one step further, generating shorter $\mathrm{A} \beta$ species.

It is possible that in the proper lipid environment, $\gamma$-secretase favors certain cleavage sites over others, resulting in differences in cleavage products when the protease is CHAPSO-solubilized vs. membrane-integrated. Cholesterol may modulate the cleavage specificity of $\gamma$-secretase (Osenkowski et al., 2008). However, a pentapeptide VVIAT was released by CHAPSO-solubilized $\gamma$ secretase with large amounts of synthetic A $\beta 43$ as a substrate (Okochi et al., 2013). Thus, it is more likely that the variable cleavages that occur as a consequence of the surrounding conditions are an inherent property of $\gamma$-secretase. When $\gamma$-secretase had higher activity in the membrane environment, a number of co-released minor peptides would be easily identified.

Most FAD mutations on PS impair the $\gamma$-secretase activities. Some mutations on PS1 reduced the cropping activity of $\gamma$-secretase (Okochi et al., 2013; Fernandez et al., 2014) and led to accumulation of longer $A \beta$ s such as $A \beta 43, A \beta 45$, and $A \beta 46$ (Shimojo et al., 2008; Quintero-Monzon et al., 2011). While A $\beta 43$ is another neurotoxic $A \beta$ species (Saito et al., 2011), the toxicity and aggregation properties of $A \beta 45$ and $A \beta 46$ are not yet understood. However, it is possible that the accumulation of longer $\mathrm{A} \beta$ induces further impairment of the $\gamma$-secretase function and accelerates the disease progression. The observation by Yagishita et al. (2008) that $A \beta 46$ accumulated in the presence of DAPT was converted to $A \beta 40$ and $A \beta 43$ even in the presence of L-685,458 ([1S-benzyl-4R-(1S-carbamoyl-2-phenylethylcarbamoyl-1S-3methylbutylcarbamoyl)-2R-hydroxy-5-phenylpentyl] carbamic acid tert-butyl ester), a transition state analog $\gamma$-secretase inhibitor, indicated that $A \beta 46$ generated as an intermediate remains bound to the catalytic site of $\gamma$-secretase. The altered binding kinetics of $\mathrm{A} \beta 46$ may result in disturbed turnover of $\gamma$-secretase.

Proteolytic cleavage of the $\alpha$-helix generally requires local unwinding to expose a scissile peptide bond to the catalytic site of the protease. The initial endopeptidase-like cleavage of the $\beta \mathrm{CTF}$ by $\gamma$-secretase may be facilitated by the flexible loose structure around the $\varepsilon$-cleavage site, which has been revealed by NMR (Sato et al., 2009; Lu and Tycko, 2011). Since $\varepsilon$-cleaved long A $\beta$ (A $\beta 49$ or $\mathrm{A} \beta 48$ ) is hardly detectable in any system (Qi-Takahara et al., 2005; Kakuda et al., 2006), it is likely that cropping proceeds swiftly in the same cellular compartment (Qi-Takahara et al., 2005), once $\varepsilon$-cleavage is initiated. The cleavage sites aligned on the surface of the $\alpha$-helix of the $\beta$ CTF transmembrane domain $(\sim 3.6$ residues for one turn of $\alpha$-helix) may encourage the recognition and/or proteolysis by $\gamma$-secretase (Qi-Takahara et al., 2005). The observations of the major three-residue spaced stepwise processing and the differential sensitivity to DAPT observed among cleavage sites are consistent with this assumption (Qi-Takahara et al., 2005). On the other hand, the release of tetra- and pentapeptides, in addition to tripeptides, may also support the theory that the fraying helix terminus generated by the cleavage promotes the next cleavage (Sato et al., 2009; Pester et al., 2013). Future structural studies may uncover hidden enzymatic properties of $\gamma$-secretase, as the recent identification of a structure homologous to carboxypeptidase within the structure of nicastrin ( $\mathrm{Lu}$ et al., 2014). The termination of the stepwise processing should release $A \beta$. Glycine residues in the transmembrane domain may determine the termination point (Munter et al., 2007; Pester et al., 2013; Lemmin et al., 2014). Alternatively, $A \beta$ may be released due to decreased hydrophobicity of the shortened $A \beta$ stub. The absence of glycine residues in the Notch and CD44 transmembrane domain (Figure 1B) supports the latter possibility. Either way, the primary cleavage site $\left(\gamma^{-}, \varepsilon^{-}\right.$, or $\left.\zeta^{-}\right)$appears to be criti$\mathrm{cal}$ in determining the final $\mathrm{A} \beta$ species produced. The properties of amino acids lining the cleavage sites are also important in determining the cleaved residues, because substitutions of those amino acids generated alternative cleavage sites (Lichtenthaler et al., 1999; Sato et al., 2005).

\section{CONCLUDING REMARKS}

The successive tripeptide-cropping pathway is the basal framework for the $\beta$ CTF cleavage by the membrane-integrated $\gamma$-secretase, but many alternative cleavages occur to release threeto six-residue peptides. There is crosstalk between the pathways involved in stepwise successive processing for $A \beta$ generation by $\gamma$-secretase. The stepwise sequential processing mechanism may be a general property of intramembrane proteolysis by the $\gamma$-secretase family of proteases (see Figure 1B). Several residuespaced cleavages have also been identified in PS (Fukumori et al., 2010) and in tumor necrosis factor- $\alpha$ (a substrate of signal peptide peptidase-like protein) (Fluhrer et al., 2006). Cleavage at three residue intervals appears to be favorable at least for $\gamma$-secretase, but it is not required. The stepwise successive processing by $\gamma$-secretase may be at work to metabolize various membrane-spanning proteins in the membrane as with the proteasome in the cytoplasm (Kopan and Ilagan, 2004), since small peptides are promptly released from the membrane. On the other hand, $\gamma$-secretase-mediated endoproteolysis plays a critical role in cellular signaling: shedding-primed $\varepsilon$-like cleavage modulates cellular signaling pathways through the released C-terminal intracellular domain (ICD), as typically observed in the Notch receptor (De Strooper and Annaert, 2010). Thus, $\gamma$-secretase may have two distinct physiological functions coupled with the proteolysis. In addition, both functions may be coordinated.

\section{ACKNOWLEDGMENTS}

I thank all the collaborators who contributed to the work presented here, particularly, Drs. Ye Qi-Takahara, Mako Takami, and Yasuo Ihara (Doshisha University). The study was supported in part by a Grant-in-Aid for Scientific Research (C) from the Japan Society for the Promotion of Science (JSPS).

\section{REFERENCES}

De Strooper, B., and Annaert, W. (2010). Novel research horizons for presenilins and $\gamma$-secretases in cell biology and disease. Annu. Rev. Cell Dev. Biol. 26, 235-260. doi: 10.1146/annurev-cellbio-100109-104117

De Strooper, B., Iwatsubo, T., and Wolfe, M. S. (2012). Presenilins and $\gamma$-secretase: structure, function, and role in Alzheimer Disease. Cold Spring Harb. Perspect Med. 2:a006304. doi: 10.1101/cshperspect.a006304 
Dimitrov, M., Alattia, J. R., Lemmin, T., Lehal, R., Fligier, A., Houacine, J., et al. (2013). Alzheimer's disease mutations in APP but not $\gamma$-secretase modulators affect $\varepsilon$-cleavage-dependent AICD production. Nat. Commun. 4, 2246. doi: 10.1038/ncomms3246

Extance, A. (2010). Alzheimer's failure raises questions about disease-modifying strategies. Nat. Rev. Drug Discov. 9, 749-751. doi: 10.1038/nrd3288

Fernandez, M. A., Klutkowski, J. A., Freret, T., and Wolfe, M. S. (2014). Alzheimer presenilin-1 mutations dramatically reduce trimming of long amyloid $\beta$ peptides $(\mathrm{A} \beta)$ by $\gamma$-secretase to increase 42 -to-40 residue A $\beta$. J. Biol. Chem. 289, 31043-30152. doi: 10.1074/jbc.M114.581165

Fluhrer, R., Grammer, G., Israel, L., Condron, M. M., Haffner, C., Friedmann, E., et al. (2006). A $\gamma$-secretase-like intramembrane cleavage of TNF $\alpha$ by the GxGD aspartyl protease SPPL2b. Nat. Cell Biol. 8, 894-896. doi: 10.1038/ncb1450

Fukumori, A., Fluhrer, R., Steiner, H., and Haass, C. (2010). Three-amino acid spacing of presenilin endoproteolysis suggests a general stepwise cleavage of $\gamma$ secretase-mediated intramembrane proteolysis. J. Neurosci. 30, 7853-7862. doi: 10.1523/JNEUROSCI.1443-10.2010

Funamoto, S., Morishima-Kawashima, M., Tanimura, Y., Hirotani, N., Saido, T. C., and Ihara, Y. (2004). Truncated carboxyl-terminal fragments of $\beta$-amyloid precursor protein are processed to amyloid $\beta$-proteins 40 and 42 . Biochemistry 43, 13532-13540. doi: 10.1021/bi049399k

Gu, Y., Misonou, H., Sato, T., Dohmae, N., Takio, K., and Ihara, Y. (2001). Distinct intramembrane cleavage of the $\beta$-amyloid precursor protein family resembling $\gamma$-secretase-like cleavage of Notch. J. Biol. Chem. 276, 35235-35238. doi: 10.1074/jbc.C100357200

Hata, S., Fujishige, S., Araki, Y., Kato, N., Araseki, M., Nishimura, M., et al. (2009). Alcadein cleavages by amyloid $\beta$-precursor protein (APP) $\alpha$ - and $\gamma$-secretases generate small peptides, p3-Alcs, indicating Alzheimer disease-related $\gamma$-secretase dysfunction. J. Biol. Chem. 284, 36024-36033. doi: 10.1074/jbc.M109.057497

$\mathrm{Hu}$, J., Xue, Y., Lee, S., and Ha, Y. (2011). The crystal structure of GXGD membrane protease FlaK. Nature 475, 528-531. doi: 10.1038/nature10218

Hur, J. Y., Welander, H., Behbahani, H., Aoki, M., Frånberg, J., Winblad, B., et al. (2008). Active $\gamma$-secretase is localized to detergent-resistant membranes in human brain. FEBS J. 275, 1174-1187. doi: 10.1111/j.1742-4658.2008. 06278.x

Iwatsubo, T., Odaka, A., Suzuki, N., Mizusawa, H., Nukina, N., and Ihara, Y. (1994). Visualization of $A \beta 42(43)$ and $A \beta 40$ in senile plaques with end-specific $A \beta$ monoclonals: evidence that an initially deposited species is A $\beta 42(43)$. Neuron 13, 45-53. doi: 10.1016/0896-6273(94)90458-8

Kakuda, N., Funamoto, S., Yagishita, S., Takami, M., Osawa, S., Dohmae, N., et al. (2006). Equimolar production of amyloid $\beta$-protein and amyloid precursor protein intracellular domain from $\beta$-carboxyl-terminal fragment by $\gamma$-secretase. J. Biol. Chem. 281, 14776-14786. doi: 10.1074/jbc.M513453200

Kopan, R., and Ilagan, M. X. (2004). $\gamma$-Secretase: proteasome of the membrane? Nat. Rev. Mol. Cell Biol. 5, 499-504. doi: 10.1038/nrm1406

Kuperstein, I., Broersen, K., Benilova, I., Rozenski, J., Jonckheere, W., Debulpaep, M., et al. (2010). Neurotoxicity of Alzheimer's disease A $\beta$ peptides is induced by small changes in the $\mathrm{A} \beta 42$ to $\mathrm{A} \beta 40$ ratio. EMBO J. 29, 3408-3420. doi: 10.1038/emboj.2010.211

Lammich, S., Okochi, M., Takeda, M., Kaether, C., Capell, A., Zimmer, A. K., et al. (2002). Presenilin-dependent intramembrane proteolysis of CD44 leads to the liberation of its intracellular domain and the secretion of an $A \beta$-like peptide. J. Biol. Chem. 277, 44754-44759. doi: 10.1074/jbc.M206872200

Lemmin, T., Dimitrov, M., Fraering, P. C., and Dal Peraro, M. (2014). Perturbations of the straight transmembrane $\alpha$-helical structure of the amyloid precursor protein affect its processing by $\gamma$-secretase. J. Biol. Chem. 289, 6763-6774. doi: 10.1074/jbc.M113.470781

Li, X., Dang, S., Yan, C., Gong, X., Wang, J., and Shi, Y. (2013). Structure of a presenilin family intramembrane aspartate protease. Nature 493, 56-61. doi: 10.1038 /nature11801

Lichtenthaler, S. F., Wang, R., Grimm, H., Uljon, S. N., Masters, C. L., and Beyreuther, K. (1999). Mechanism of the cleavage specificity of Alzheimer's disease $\gamma$-secretase identified by phenylalanine-scanning mutagenesis of the transmembrane domain of the amyloid precursor protein. Proc. Natl. Acad. Sci. U.S.A. 96, 3053-3058. doi: 10.1073/pnas.96.6.3053

Lu, P., Bai, X. C., Ma, D., Xie, T., Yan, C., Sun, L., et al. (2014). Three-dimensional structure of human $\gamma$-secretase. Nature 512, 166-170. doi: 10.1038/nature 13567
Lu, W. M., and Tycko, R. (2011). Evidence from solid-state NMR for nonhelical conformations in the transmembrane domain of the amyloid precursor protein. Biophys. J. 100, 711-719. doi: 10.1016/j.bpj.2010.12.3696

Matsumura, N., Takami, M., Okochi, M., Wada-Kakuda, S., Fujiwara, H., Tagami, S., et al. (2014). $\gamma$-Secretase associated with lipid rafts: multiple interactive pathways in the stepwise processing of $\beta$-carboxyl-terminal fragment. J. Biol. Chem. 289, 5109-5121. doi: 10.1074/jbc.M113.510131

Munter, L. M., Voigt, P., Harmeier, A., Kaden, D., Gottschalk, K. E., Weise, C., et al. (2007). GxxxG motifs within the amyloid precursor protein transmembrane sequence are critical for the etiology of A $\beta 42$. EMBO J. 26, 1702-1712. doi: 10.1038/sj.emboj.7601616

Okamoto, I., Kawano, Y., Murakami, D., Sasayama, T., Araki, N., Miki, T., et al. (2001). Proteolytic release of CD44 intracellular domain and its role in the CD44 signaling pathway. J. Cell Biol. 155, 755-762. doi: 10.1083/jcb.200108159

Okochi, M., Steiner, H., Fukumori, A., Tanii, H., Tomita, T., Tanaka, T., et al. (2002). Presenilins mediate a dual intramembranous $\gamma$-secretase cleavage of Notch-1. EMBO J. 21, 5408-5416. doi: 10.1093/emboj/cdf541

Okochi, M., Tagami, S., Yanagida, K., Takami, M., Kodama, T. S., Mori, K., et al. (2013). $\gamma$-Secretase modulators and presenilin 1 mutants act differently on presenilin $/ \gamma$-secretase function to cleave $A \beta 42$ and $A \beta 43$. Cell Rep. 3, 42-51. doi: 10.1016/j.celrep.2012.11.028

Olsson, F., Schmidt, S., Althoff, V., Munter, L. M., Jin, S., Rosqvist, S., et al. (2014). Characterization of intermediate steps in amyloid $\beta(A \beta)$ production under near-native conditions. J. Biol. Chem. 289, 1540-1550. doi: 10.1074/jbc.M113.498246

Osenkowski, P., Ye, W., Wang, R., Wolfe, M. S., and Selkoe, D. J. (2008). Direct and potent regulation of $\gamma$-secretase by its lipid microenvironment. J. Biol. Chem. 283, 22529-22540. doi: 10.1074/jbc.M801925200

Pester, O., Barrett, P. J., Hornburg, D., Hornburg, P., Pröbstle, R., Widmaier, S., et al. (2013). The backbone dynamics of the amyloid precursor protein transmembrane helix provides a rationale for the sequential cleavage mechanism of $\gamma$-secretase. J. Am. Chem. Soc. 135, 1317-1329. doi: 10.1021/ja3112093

Piao, Y., Kimura, A., Urano, S., Saito, Y., Taru, H., Yamamoto, T., et al. (2013). Mechanism of intramembrane cleavage of alcadeins by $\gamma$-secretase. PLoS ONE 8:e62431. doi: 10.1371/journal.pone.0062431

Qi-Takahara, Y., Morishima-Kawashima, M., Tanimura, Y., Dolios, G., Hirotani, N., Horikoshi, Y., et al. (2005). Longer forms of amyloid $\beta$ protein: implications for the mechanism of intramembrane cleavage by $\gamma$-secretase. J. Neurosci. 25, 436-445. doi: 10.1523/JNEUROSCI.1575-04.2005

Quintero-Monzon, O., Martin, M. M., Fernandez, M. A., Cappello, C. A., Krzysiak, A. J., Osenkowski, P., et al. (2011). Dissociation between the processivity and total activity of $\gamma$-secretase: implications for the mechanism of Alzheimer's disease-causing presenilin mutations. Biochemistry 50, 9023-9035. doi: 10.1021/bi2007146

Saito, T., Suemoto, T., Brouwers, N., Sleegers, K., Funamoto, S., Mihira, N., et al. (2011). Potent amyloidogenicity and pathogenicity of A $\beta 43$. Nat. Neurosci. 14, 1023-1032. doi: 10.1038/nn.2858

Sastre, M., Steiner, H., Fuchs, K., Capell, A., Multhaup, G., Condron, M. M., et al. (2001). Presenilin-dependent $\gamma$-secretase processing of $\beta$-amyloid precursor protein at a site corresponding to the S3 cleavage of Notch. EMBO Rep. 2, 835-841. doi: 10.1093/embo-reports/kve180

Sato, C., Morohashi, Y., Tomita, T., and Iwatsubo, T. (2006). Structure of the catalytic pore of $\gamma$-secretase probed by the accessibility of substituted cysteines. $J$. Neurosci. 26, 12081-12088. doi: 10.1523/JNEUROSCI.3614-06.2006

Sato, T., Dohmae, N., Qi, Y., Kakuda, N., Misonou, H., Mitsumori, R., et al. (2003). Potential link between amyloid $\beta$-protein 42 and C-terminal fragment $\gamma 49-99$ of $\beta$-amyloid precursor protein. J. Biol. Chem. 278, 24294-24301. doi: 10.1074/jbc.M211161200

Sato, T., Tang, T. C., Reubins, G., Fei, J. Z., Fujimoto, T., Kienlen-Campard, P., et al. (2009). A helix-to-coil transition at the $\varepsilon$-cut site in the transmembrane dimer of the amyloid precursor protein is required for proteolysis. Proc. Natl. Acad. Sci. U.S.A. 106, 1421-1426. doi: 10.1073/pnas.0812261106

Sato, T., Tanimura, Y., Hirotani, N., Saido, T. C., Morishima-Kawashima, M., and Ihara, Y. (2005). Blocking the cleavage at midportion between $\gamma$ - and $\varepsilon$-sites remarkably suppresses the generation of amyloid $\beta$-protein. FEBS Lett. 579, 2907-2912. doi: 10.1016/j.febslet.2005.04.037

Schroeter, E. H., Kisslinger, J. A., and Kopan, R. (1998). Notch-1 signalling requires ligand-induced proteolytic release of intracellular domain. Nature 393, 382-386. doi: $10.1038 / 30756$ 
Selkoe, D. J. (2011). Alzheimer's disease. Cold Spring Harb. Perspect Biol. 3:a004457. doi: 10.1101/cshperspect.a004457

Shah, S., Lee, S. F., Tabuchi, K., Hao, Y. H., Yu, C., LaPlant, Q., et al. (2005). Nicastrin functions as a $\gamma$-secretase-substrate receptor. Cell 122, 435-447. doi: 10.1016/j.cell.2005.05.022

Shimojo, M., Sahara, N., Mizoroki, T., Funamoto, S., Morishima-Kawashima, M., Kudo, T., et al. (2008). Enzymatic characteristics of I213T mutant presenilin- $1 / \gamma$-secretase in cell models and knock-in mouse brains: familial Alzheimer disease-linked mutation impairs $\gamma$-site cleavage of amyloid precursor protein C-terminal fragment $\beta$. J. Biol. Chem. 283, 16488-16496. doi: 10.1074/jbc.M801279200

Tagami, S., Okochi, M., Yanagida, K., Ikuta, A., Fukumori, A., Matsumoto, N., et al. (2008). Regulation of Notch signaling by dynamic changes in the precision of S3 cleavage of Notch-1. Mol. Cell Biol. 28, 165-176. doi: 10.1128/MCB.00863-07

Takami, M., Nagashima, Y., Sano, Y., Ishihara, S., Morishima-Kawashima, M., Funamoto, S., et al. (2009). $\gamma$-Secretase: successive tripeptide and tetrapeptide release from the transmembrane domain of $\beta$-carboxyl terminal fragment. J. Neurosci. 29, 13042-13052. doi: 10.1523/JNEUROSCI.2362-09.2009

Tolia, A., Chavez-Gutierrez, L., and De Strooper, B. (2006). Contribution of presenilin TMDs 6 and 7 to a water-containing cavity in the $\gamma$-secretase complex. J. Biol. Chem. 281, 27633-27642. doi: 10.1074/jbc.M604997200

Vetrivel, K. S., Cheng, H., Lin, W., Sakurai, T., Li, T., Nukina, N., et al. (2004). Association of $\gamma$-secretase with lipid rafts in post-Golgi and endosome membranes. J. Biol. Chem. 279, 44945-44954. doi: 10.1074/jbc.M407986200

Vetrivel, K. S., and Thinakaran, G. (2010). Membrane rafts in Alzheimer's disease $\beta$-amyloid production. Biochim. Biophys. Acta 1801, 860-867. doi: 10.1016/j.bbalip.2010.03.007

Wada, S., Morishima-Kawashima, M., Qi, Y., Misono, H., Shimada, Y., OhnoIwashita, Y., et al. (2003). $\gamma$-Secretase activity is present in rafts but is not cholesterol-dependent. Biochemistry 42, 13977-13986. doi: 10.1021/bi034904j

Weidemann, A., Eggert, S., Reinhard, F. B., Vogel, M., Paliga, K., Baier, G., et al. (2002). A novel $\varepsilon$-cleavage within the transmembrane domain of the Alzheimer amyloid precursor protein demonstrates homology with Notch processing. Biochemistry 41, 2825-2835. doi: 10.1021/bi015794o

Wolfe, M. S., Xia, W., Ostaszewski, B. L., Diehl, T. S., Kimberly, W. T., and Selkoe, D. J. (1999). Two transmembrane aspartates in presenilin-1 required for presenilin endoproteolysis and $\gamma s s-$ secretase activity. Nature 398, 513-517. doi: $10.1038 / 19077$

Yagishita, S., Morishima-Kawashima, M., Ishiura, S., and Ihara, Y. (2008). A $\beta 46$ is processed to $A \beta 40$ and $A \beta 43$, but not to $A \beta 42$, in the low density membrane domains. J. Biol. Chem. 283, 733-738. doi: 10.1074/jbc.M707103200

Yagishita, S., Morishima-Kawashima, M., Tanimura, Y., Ishiura, S., and Ihara, Y. (2006). DAPT-induced intracellular accumulations of longer amyloid $\beta$-proteins: further implications for the mechanism of intramembrane cleavage by $\gamma$-secretase. Biochemistry 45, 3952-3960. doi: 10.1021/ bi0521846

Yanagida, K., Okochi, M., Tagami, S., Nakayama, T., Kodama, T. S., Nishitomi, K., et al. (2009). The 28-amino acid form of an APLP1-derived A $\beta$-like peptide is a surrogate marker for $\mathrm{A} \beta 42$ production in the central nervous system. $E M B O$ Mol. Med. 1, 223-235. doi: 10.1002/emmm.200900026

Zhao, G., Mao, G., Tan, J., Dong, Y., Cui, M. Z., Kim, S. H., et al. (2004). Identification of a new presenilin-dependent $\zeta$-cleavage site within the transmembrane domain of amyloid precursor protein. J. Biol. Chem. 279, 50647-50650. doi: 10.1074/jbc.C400473200

Conflict of Interest Statement: The author declares that the research was conducted in the absence of any commercial or financial relationships that could be construed as a potential conflict of interest.

Received: 27 September 2014; accepted: 11 November 2014; published online: 27 November 2014.

Citation: Morishima-Kawashima M (2014) Molecular mechanism of the intramembrane cleavage of the $\beta$-carboxyl terminal fragment of amyloid precursor protein by $\gamma$-secretase. Front. Physiol. 5:463. doi: 10.3389/fphys.2014.00463

This article was submitted to Membrane Physiology and Membrane Biophysics, a section of the journal Frontiers in Physiology.

Copyright (๑) 2014 Morishima-Kawashima. This is an open-access article distributed under the terms of the Creative Commons Attribution License (CC BY). The use, distribution or reproduction in other forums is permitted, provided the original author(s) or licensor are credited and that the original publication in this journal is cited, in accordance with accepted academic practice. No use, distribution or reproduction is permitted which does not comply with these terms. 